\title{
"Basal Cell Blanche": A Diagnostic Maneuver to Increase Early Detection of Basal Cell Carcinomas
}

\author{
Olivia Leigh Quach, AB, Megan Barry, MD, Allison Roberts Cruse, MD, and
}

Barbara B. Wilson, $M D$

Basal cell carcinomas represent one of the most common skin cancers and often present initially in the primary care setting. Subtle basal cell carcinomas may be difficult to detect, and early detection of these carcinomas remains important in limiting patient morbidity. In this article, we present a simple diagnostic maneuver, "basal cell blanche," to increase early detection of basal cell carcinomas. (J Am Board Fam Med 2016;29:408-410.)

Keywords: Cancer Screening; Carcinoma, Basal Cell; Dermatology; Skin Cancer

Early detection of subtle basal cell carcinomas likely results in smaller excisions and consequently less morbidity for patients. A simple maneuver of stretching the skin overlying the basal cell carcinoma causes it to blanche, thereby making an almost invisible basal cell carcinoma to turn white and become more apparent to the observer.

This diagnostic maneuver was first described by Mellor et $\mathrm{al}^{1}$ as a way to facilitate diagnosis and complete excision of basal cell carcinomas. Mellor et al explained the efficacy of this maneuver by describing a color change that more clearly defines tumor boundaries during the stretch maneuver. The blood microvessels within a basal cell carcinoma are distinctly different from those in the surrounding skin, marking a transition between the tumor and the surrounding dermis; stretching the skin results in the disappearance of red cells within the vessels, enhancing the clinically distinct pearly opalescence of the tumor. A related version

This article was externally peer reviewed.

Submitted 3 August 2015; revised 31 December 2015; accepted 6 January 2016.

From the University of Virginia School of Medicine, Charlottesville (OLQ); the Department of Dermatology, University of Virginia Health System, Charlottesville (MB, BBW); and the Department of Dermatology, University of Mississippi, Jackson (ARC).

Funding: none.

Conflict of interest: none declared.

Corresponding author: Olivia Leigh Quach, AB, 1221 Lee St, PO Box 800718, University of Virginia Health System, Charlottesville, VA 22908-0718 (E-mail: olq2uf@virginia. edu). of this technique was described by Imran et $\mathrm{al}^{2}$ as the "reverse stretch test," in which the skin is pinched to accentuate the less pliable tissue present in the margins of a basal cell carcinoma.

In our practice we call this maneuver the "basal cell blanche" to highlight the color change that occurs in a basal cell carcinoma when the skin is stretched; we photographically demonstrate it here. In Figure 1 there is a barely visible pink discoloration on the posterior earlobe. In Figure 2, after stretching the skin, an obvious pearly papule appears. In this case biopsy subsequently confirmed a diagnosis of basal cell carcinoma. Without stretching the skin, this lesion would likely have been overlooked. We prefer the term basal cell blanche to stretch test because this technique can also be performed in areas where stretching the overlying skin is not possible, such as the nasal ala; the basal cell blanche technique can be used by inserting a cotton-tipped applicator just inside the ala and pressing up against the skin (Figures 3 and 4).

The effectiveness of this technique for delineating basal cell carcinoma margins was evaluated in 2012 by Shalom et al. ${ }^{3}$ They compared 596 patients with biopsy-proven basal cell carcinoma, 249 of whom did not have the stretch test performed to define margins before excision and 347 of whom were evaluated by the stretch test. Results showed that the rate of incompletely excised basal cell carcinomas decreased significantly among the group of patients in which the stretch technique was ap- 
Figure 1. A barely visible pink discoloration is present on the posterior earlobe.

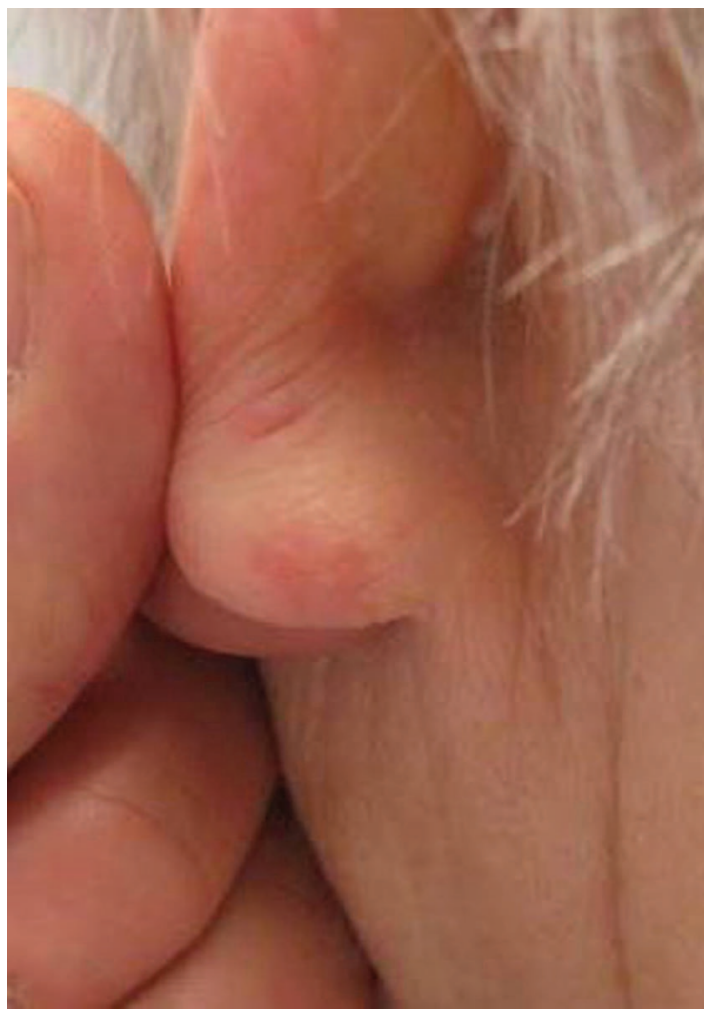

Figure 2. After stretching the skin, an obvious pearly papule appears.

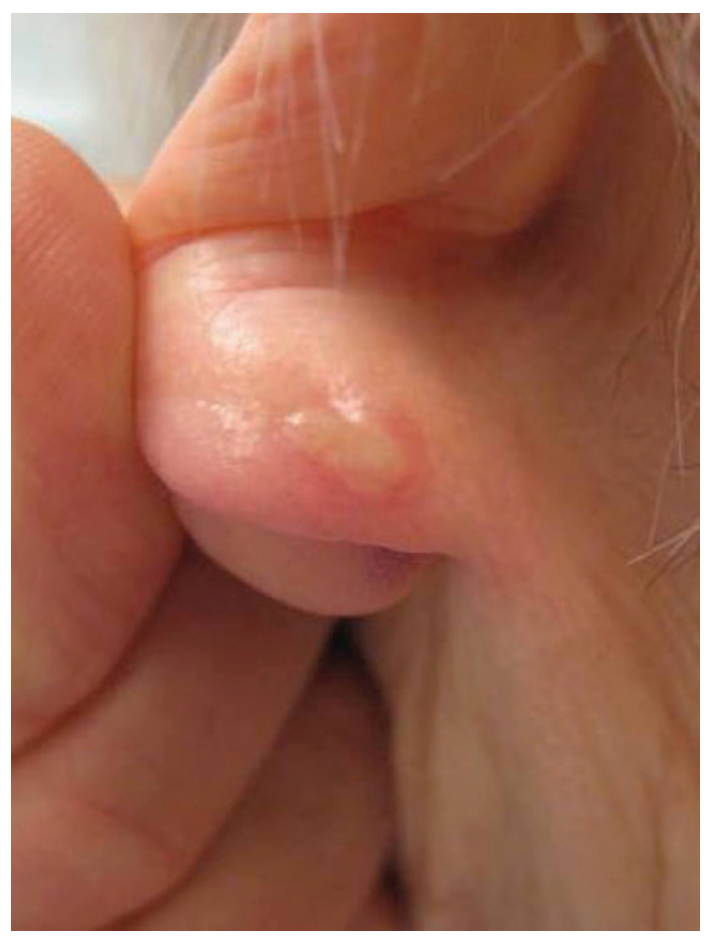

Figure 3. Faint erythema is noted on the right anterior ala.

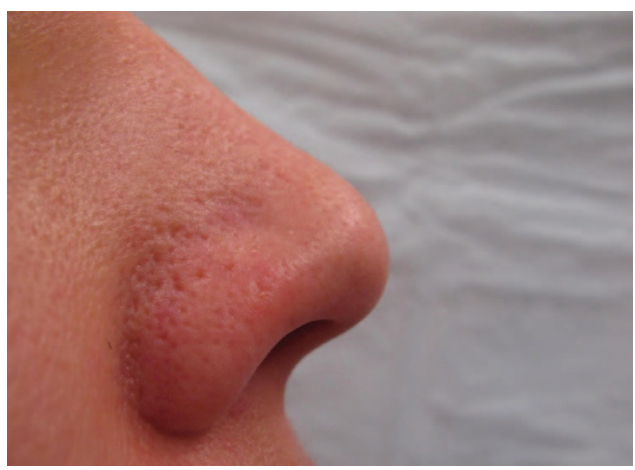

plied-from $6.4 \%$ (16 of 249 ) to $1.7 \%$ (6 of 347 ) $(P<.05)$.

It is important to note that in addition to clinical maneuvers such as the basal cell blanche, dermoscopy can be a valuable tool in diagnosing suspected basal cell carcinomas. We believe that the blanche test remains an important clinical tool, however, because this maneuver can help the physician locate these lesions in the first place, after which the diagnosis can be confirmed with dermoscopy. In addition, although dermoscopy has been found to increase the accuracy of dermatologists' diagnoses of basal cell carcinomas, ${ }^{4}$ the introduction of dermoscopy has been a relatively recent addition to the primary care skin cancer curriculum; the first intervention was described in the literature in 2006, and the first American Academy of Family Physicians dermoscopy course occurred in $2009 .{ }^{5}$ As opposed to dermoscopy, the basal cell blanche test can be used by both specialists and primary care practitioners alike without formal training and can be used as an adjunct to dermoscopy and visual evaluation.

Figure 4. A 4-mm pearly macule becomes visible after stretching the skin with a cotton-tipped applicator.

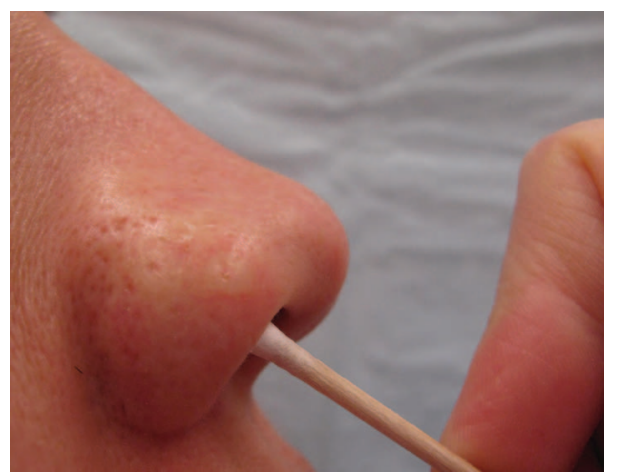


At our institution we stress the importance of "seeing with the hands"- - touching the skin during the physical examination-to enhance diagnosis. This simple maneuver to assess for basal cell blanche can be a useful adjunct to other diagnostic techniques and can thereby help improve the early diagnosis of basal cell carcinoma and the accuracy of determining margins during excision.

\section{References}

1. Mellor RH, Bulstrode N, Withey S, Moss AL, Mortimer PS. The stretch test in basal cell carcinoma: a clinical indicator of tumour. Br J Plast Surg 2002;55: 594-5.
2. Imran D, Mandal A, Dickson MG. Reverse stretch test in basal cell carcinoma. Plast Reconstr Surg 2004;114:267-8.

3. Shalom A, Westreich M, Schein O, Hadad E. Stretch test: effectiveness in identifying basal cell carcinoma borders. Ann Plast Surg 2012;68:72-3.

4. Lallas A, Argenziano G, Zendri E, et al. Update on non-melanoma skin cancer and the value of dermoscopy in its diagnosis and treatment monitoring. Expert Rev Anticancer Ther 2013;13:541-58.

5. Goulart JM, Quigley EA, Dusza S, et al; INFORMED (INternet curriculum FOR Melanoma Early Detection) Group. Skin cancer education for primary care physicians: a systematic review of published evaluated interventions. J Gen Intern Med 2011;26:1027-35. 